\title{
Theoretical Mechanics of Judgment Training in Aviation: Using Set Theory and Probability Statements in Instructional Design
}

\author{
Todd P. Hubbard \\ Oklahoma State University
}

\begin{abstract}
Aeronautical Decision Making (ADM) in student pilots has been governed by Advisory Circular 6022 since 1991, and theoretically supported by studies conducted in the 1980s. What has been missing in some of these studies is direct access to the nature of judgment within decision-making. Judgment has always been the by-product of decision-making, not the chief focus. This essay concentrated on the response type and headwork portions of the ADM process, the first four steps of Jensen's (1995) detailed decision model, and the rational judgment portion of the Theory of Signal Detectability (TSD) (Jensen, 1995). Venn diagrams were used to express a new concept known as tensional meaningfulness and to express in theoretical terms how phenomena within the Venn diagrams related to each other. Orasanu's (1993) three types of decisions provided the backdrop for these Venn visualizations. These theoretical relationships were then translated into practical guidance for instruction in the classroom, instruction in the simulator, and testing strategies.
\end{abstract}

\section{INTRODUCTION}

For professional pilots, an accurate or situationally relevant decision is based on a sound foundation of judgment, accrued over years of experience and much regulation. If pilot judgment is faulty, who is to know? If decision-making is faulty, it seems that everyone knows. Poor simulator performance, in-flight incidents or accidents might provide evidence of poor judgment, but in the crew environment, some poor judgment can be mitigated by good crew resource management. In other words, poor judgment is bypassed, not dealt with.

In Jensen's (1995) view, the reason why bad decisions are made is because there is no concerted effort to develop judgment in student pilots, other than what is naturally acquired in the course of pilot training. Although Jensen's views appear to be dated, there is a logical assumption being made here. Pilot judgment can be built, one scenario at a time, and this training should commence the very first day of pilot training, no matter where that training is conducted (military or civilian). Jensen's insistence on a concerted effort for judgment training can be equated with what Clark (2005) described as intentional learning.

It is important to note that in the 1980s several studies were commissioned by the Federal Aviation Administration and Embry-Riddle Aeronautical University to determine if judgment training reduced the number of judgment-related errors in student, not commercial airline pilots (Berlin et al., 1982; Diehl \& Lester, 1987). The outcome showed a significant advantage in judgment-trained participants over those receiving conventional training, without a specific emphasis on judgment. Berlin et al. (1982) found that judgment-trained student pilots made $16 \%$ fewer judgment errors.

\section{Judgment and Decision-Making in the Airlines}

For a moment, the course of this paper diverts to commercial airline pilot judgment, but only to make a point about how judgment training is conducted, and then the attention will be brought back to student pilots in collegiate programs. Airline pilots pore over volumes of NTSB aircraft accident reports, to find out what went wrong and then to determine how in the future these same mistakes could be averted. In U.S. air carrier training departments, studying aircraft accident reports is just one way to stay ahead of errors. Other programs such as Line Oriented Flight Training (LOFT), Line Operations Safety Audits (LOSA), the Aviation Safety Action Program (ASAP), and the Advance Qualification Program (AQP) are used as quality enhancement tools to ensure a broader margin of safety and to improve judgment in an environment where the lack of judgment will not hurt anyone (Mulqueen, Baker, \& Dismukes, 2002). Over 30,000 pilots believed that these training programs were useful 
and that they made a difference in how they behaved as a crewmember (Beaubien \& Baker, 2002). If thousands of pilots think these programs are useful, then judgment training should begin sooner, not later.

Beaubien and Baker (2002) claimed that if CRM training were part of pilot training, one should see an improvement in judgment and decision-making, because judgment and decisionmaking are integral parts of the training curriculum: it is intentional and it has government attention (Department of Transportation [DOT], 2004). In practice, the success of judgment training within CRM courses is due in large part to the mix of classroom, simulator, and flight contexts of learning (Cook, Beneigh, \& Clark, 2001; Hoover \& Russ-Eft, 2005; Lofaro \& Smith, 2001). CRM courses that do not integrate training devices with the classroom experience are less effective and they do not assess judgment within the context of flight. This point was made by many individuals who attended the 2007 CRM Vectors conference and their recent input seems to echo what has been said in past (Beneigh \& Hubbard, 2007).

\section{Judgment and Decision-Making in Collegiate Programs}

The following comments are perceptions drawn from flight training in collegiate programs, on the flight line and in the classroom. The citations are old, but the findings are still on track. Flight examiners, Certified Flight Instructors, and professors supporting collegiate professional pilot programs have many ways of developing judgment in student pilots (Diehl \& Lester, 1987). The means by which judgment is built are also the means by which judgment is assessed. On the flight line student pilots take paper and pencil tests and computer-based tests; they orally communicate resolutions to situational problems posed by their flight instructors, they complete training sessions in the simulator, and they complete flights in the aircraft. If the training curriculum does not specifically include a section on judgment, then one can assume that judgment is only the byproduct of training and is not an intentionally emphasized and tested part of that training.

Professors who educate professional pilot students through theory-based courses, such as Ethics, Law, CRM or Human Factors, build judgment in their students through the lens of other's experience in the real world-the world outside of the classroom. Reviewing NTSB accident reports is one method of integrating actual experiences of pilots, and is perhaps one of the oldest ways to introduce pilots to judgment and decision-making. Supported by simulator sessions, perhaps a better way forward is to use texts that go beyond the accident report, into the psyche of the pilot and the psyche of the pilot's airline company, such as The Limits of Expertise, by Dismukes, Berman, and Loukopoulos (2007). Students are asked to go beyond the obvious or the reported proximate cause and find other clues for poor performance, which expands classroom discussion to include issues of judgment. Given the assumption that a pilot does not intend to make bad decisions and bring harm on him or her and the passengers on board, there might be other reasons for the mistakes. This is the point being made in Limits of Expertise.

Judgment training post 1980s has been built on the foundational principles found in Advisory Circular (AC) 60-22 (DOT, 1991). These principles are distillations of studies conducted by Jensen, Adrion, and Maresh with the U.S. Air Force (Jensen, 1995) and other studies such as those by Berlin et al., (1982) and Diehl and Lester (1987). Therefore, to understand the theoretical underpinnings of AC 60-22, Aeronautical Decision Making (ADM) is to understand the theoretical underpinnings of the aforementioned studies.

The FAA, even in its regulatory role, is reluctant to write an advisory circular if it is not based on dozens of corroborating studies, in a way similar to how AC 60-22 was created. A case in point is the June 18, 1996 study on The Interfaces Between Flightcrews and Modern Flight Deck Systems. In the preface of the co-chairpersons, the FAA listed those who contributed to the study. Besides the FAA, the European Joint Aviation Authorities, and "technical advisors" from The Ohio State University, the University of Illinois, and the University of Texas participated. Those tracking automation studies would have guessed the names of those contributing from each university. Nadine Sarter, the University of Illinois representative, has academic and professional connections to the Ohio State University through Richard Jensen and David Woods. Bob Helmreich, the University of Texas 
(Austin) representative, was the most recognizable name in human factors at UT in the 1980s and 90s, particularly in the area of CRM. And David Woods, the Ohio State University representative, is interconnected as stated earlier. The FAA had commissioned studies through these universities, and it was these universities that established the theoretical approach used by the FAA, and perhaps the European JAA.

Wherever judgment and decision-making training occurs today, it is marked by the findings of those earlier studies - funded by the FAA - that established the theoretical basis on which training would be conducted and the outcomes assessed. If theory and practice are bookends between which pilot instructors build better pilots, then paper and pencil tests are the tools used to assess the student's knowledge of theory and simulator scenario training is the tool used to assess both judgment and decision-making (DOT, 1991; Jensen, 1995).

\section{Special Focus and Limited View}

Having completed a concise history of the foundational elements of judgment and decisionmaking training and the pivotal studies that first influenced this type of training, there is now a shift toward the theoretical underpinnings of judgment itself. Since this paper is more akin to an essay on theoretical methodology, gone are the very familiar figures depicting the entire decision cycle for pilots. This paper does not address the entire decision cycle, as depicted and described in AC 60-22 (DOT, 1991). This paper instead focuses only on the response type and headwork portions of the aeronautical decision making process, as depicted in Figure 2 of AC 60-22 (not appearing herein). In terms of JAMJET (Jensen, Adrion and Maresh, Judgment Assessment Technique), this paper focuses on problem vigil, recognition, diagnosis, and alternative generation from within the detailed judgment model in Jensen (1995, p. 37). Regarding the Theory of Signal Detectability (TSD), this paper is only interested in the rational judgment part of the theory, which coincides with at least four of the steps in the detailed judgment model (listed above).

This paper provides insights into how judgment training can be developed for collegiate aviation programs within this narrow focus. Throughout the paper, the reader will see illustrations of how students can be prepared to receive judgment training, how instructors should proceed when building judgment scenarios for student pilots, and how instructional designers can use the logical forms in Venn diagrams to construct meaningful curricula. As a means to keep the paper relevant to current thinking about judgment and decision-making, work by the following persons was analyzed (Bass \& Radzio; 2003; Jensen, 1995; Mauro, Barshi, Pederson, \& Bruinicks, 2001; O’Hare, 2003; Orasanu, 1993). It is important to note here that even though work by Orasanu and Jensen date back to the 1990s, and that many of the other references are hedging on being old news, their combined work continues to challenge and inform scholars in the $21^{\text {st }}$ century. What follows are parts of a broader discussion on the theory of judgment.

\section{PART 1: THE THEORETICAL MECHANICS OF JUDGMENT AND DECISIONS}

Keeping in mind that the chief aim of this paper is to provide a bridge between theory and practice in judgment training, it is important to separate theory from practice and then knit it back together by the end. First, the reader will be treated to a section on the proposed theory of tensional meaningfulness as it relates to the valuation of decisions made while solving problems. To do this, brain biology, probability judgments (Venn diagrams), and the mechanics of attention and inhibition must be explained, at least partly. It is beyond the reach of this paper to thoroughly inform the reader of all that can be known about judgment and decisions within the purview of cognitive psychology, but some exposure is necessary if the end goal is to be attained. Second, the theoretical must be balanced with the experiential. Practical tips on how to design judgment training and how to properly assess judgment after training will be described and illustrated. As a start to this process, we need a skeletal framework upon which we can build theory and later practice. Orasanu (1993) and Mauro et al. (2001) have provided this framework.

In a chapter by Orasanu (1993), she listed three categories of decisions made by pilots in the cockpit as knowledge-based (ill-defined problems), knowledge-based (well-defined problems), and rule-based (condition-action rules) 
(p. 138). Mauro et al. (2001) presented an alternative list some years later (analytical, associative, and codified).

There are some obvious pairings or logically intuitive agreements between the two lists. For example, analytical decisions can be paired with knowledge-based (ill-defined problems), associative decisions can be paired with knowledge-based (well-defined problems), and codified decisions are naturally paired to Orasanu's rule-based decisions. These pairings, put in display form, would look like Figure 1.

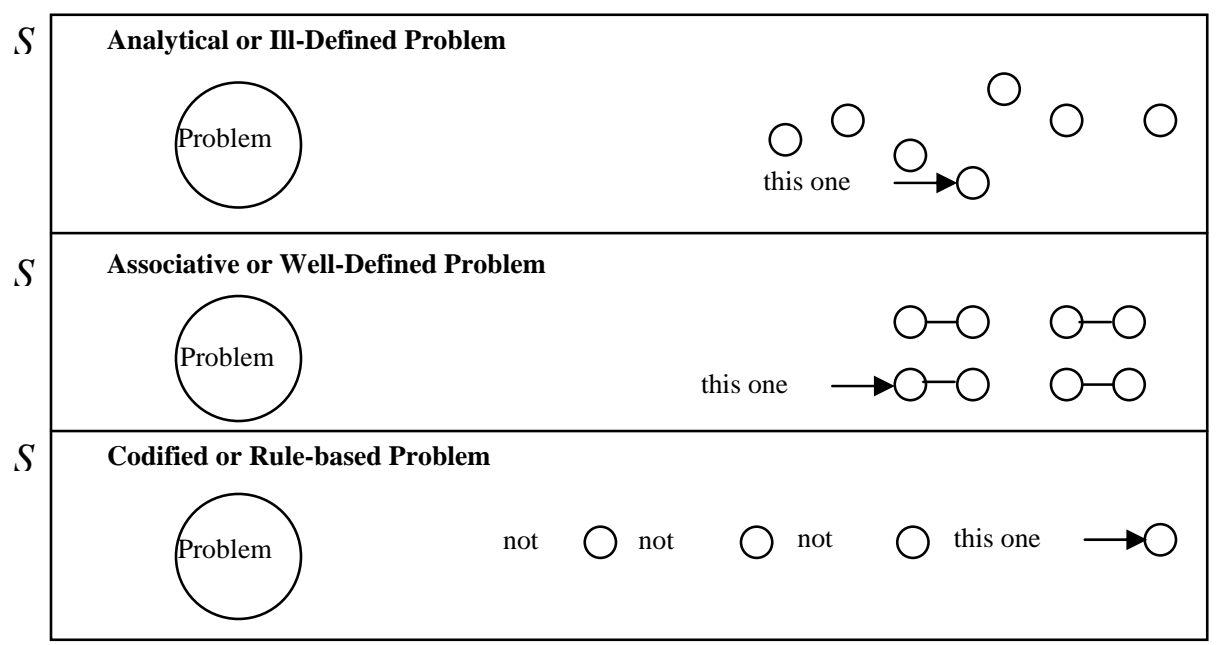

Figure 1. Category Pairings of Decision Types

Figure 1 is divided into three parts, separating each decisional category. On the left side of each division an $S$ appears. $S$ is the space within each rectangle. On the right of each rectangle there is a depiction of the logical induction; however, it is not a depiction of how an individual processes information or makes decisions based on judgment. It merely illustrates the three types of decisions that pilots make.

\section{Judgment Development Though Tensional Meaningfulness}

Pilot training in collegiate aviation programs has matured over the decades. Many of the enhancements made in pilot training have been the result of studies by behavioral and cognitive psychologists who have had a special interest in aviation and pilot training. They use a special vocabulary to explain phenomena that describe specific qualities or characteristics of each phenomenon. These phenomena have simpler names outside the scientific community, but in keeping with the protocols of technical writing, the use of special terms ensures accuracy. These special terms will be described in reader appropriate language to help prevent frustration.

One of these special terms is tension. Engineers appreciate the term as a means to describe load. Artists use it to describe balance within a painting. Sociologists use tension to describe effects of group interaction. But in this essay the term takes on a new meaning: one not found in textbooks.

Tensional meaningfulness is an invented term, and although it was not derived from studies in cognitive psychology, it can be explained by use of cognitive psychology. Without going into too much detail just yet, an illustration of tensional meaningfulness will have to suffice for now. Picture a flat surface upon which there is a thin layer of iron filings. Imagine laying a bar magnet on that layer of iron filings, such that the negative end of the magnet faces away from an opposing positive end of the magnet. If the experiment is done correctly, you should see what is depicted in Figure 2. What had been invisible becomes visible in the presence of the magnets. What had been a disorganized layer of iron filings, took on shape and significance when the magnet was placed on the filings. Tensional meaningfulness is what is between and around the bipolar magnet after it is placed on the iron filings.

Perhaps not so surprisingly, some diagrams of how judgment and decisions interact look like a magnetic field. Cooksey's Lens Decomposition Judgment model, displayed in a study by Bass and Radzio (2003) illustrates this point (Figure 3). 


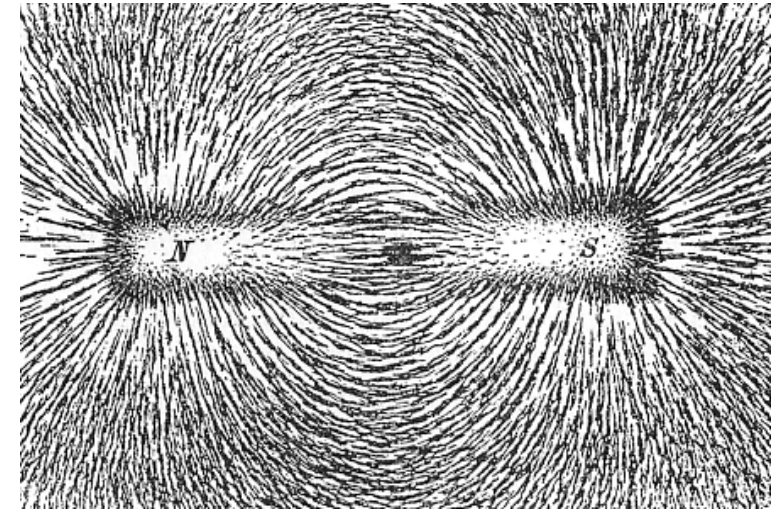

Figure 2. Magnetic Field Illustrated

It is interesting to note that the intervening cue utilizations and ecological validities have no meaningfulness unless put in relation to criterion and cues or judgment and cues, just like gender variables remain hidden until put in relationship to the opposition of the ideal masculine and ideal feminine.

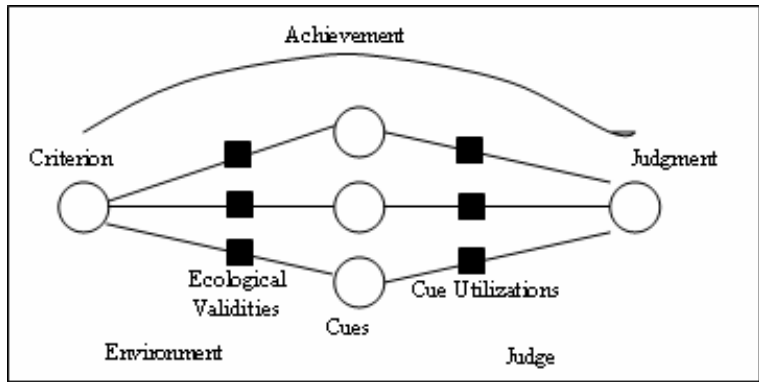

Figure 3. Lens Decomposition Model (adapted from Bass \& Radzio, 2005, p. 76)

In tensional meaningfulness terms, judgment is what lies between two points in opposition: the decision to do something and the decision not to do something. Using the tensional meaningfulness expressed in the magnet illustration, suppose instead of iron filings there is a layer of knowledge laid to rest on the flat surface without organization. Suppose a problem is introduced, which Jensen(1995) described as problem vigil and recognition. Ultimately, the problem will be resolved correctly when it is properly diagnosed and when one decision can be distilled from all other possibilities. Put in opposition to each other, the tensional field is that which operates around and between two poles, which for the present can be represented as $\mathrm{A}$ and $\sim \mathrm{A}$. All things having to do with the problem can be found between $A$ - the pole representing the one decision that is the very best decision-and $\sim \mathrm{A}$ - the pole representing a decision that has nothing to do with any accurate solution of the problem, but which is just outside possibility. In tensional terms, $\mathrm{A}$ is the polar opposite of $\sim$ A (read "not" A). All that resides around and in between these poles are possible solutions, without any ordering as to effectiveness. Only judgment can differentiate between one possible solution and another possible solution. In terms of the detailed judgment model, this is the stage where alternatives are identified and risks assessed (Jensen, 1995, p. 37). If using the TSD model, all the steps having to do with rational judgment have been energized (Jensen, 1995).

Perhaps one of the most significant statements that will be made and supported in this paper is the statement that judgment is not decision. Judgment is the knowledge and ability that allows a person to intervene in the decision cycle and make a selection from all possible alternatives, as defined by $\mathrm{A}$ and $\sim \mathrm{A}$, with an apparent belief that this, and not another, possibility is the best for the moment. This theoretical approach will be explained further.

\section{Quick Review of the Cognitive Process}

Judgment development depends to a large extent on the raw materials in each student pilot: his or her intellectual ability in particular. Intellectual ability is not something one can change. One can gild the lily, with all sorts of academic achievement, but one's intellectual ability remains steadfast (Gardner, 1999). Gardner believed, and still does believe that there are several types of intelligence, some being more conducive to careers in science and technology and others more conducive to careers in public service. However, no matter what a person's intelligence is called, the unifying factor for all student pilots is brain biology, to include brain chemistry.

Based on neuroscience, the biological center of decision-making is largely controlled by the frontal lobe, just behind the forehead (Barkley \& Grodzinsky, 1994). It has been called the executive control center by some, because incoming information from other parts of the brain eventually gets sorted out in the frontal lobe. Brain research examined by Goleman (1995) indicated that higher functions of the brain are engaged very quickly after initial excitation, when in the presence of an emotionally significant event. 
For example, if a child falls into a backyard swimming pool, adults will jump in the water to save the child. The fight or flight mechanism in our brains causes immediate action. Save the child. Forget about how wet you will get or that your billfold is in your pants pocket. An individual can react immediately or pause long enough to shift to a higher reasoning ability. In the case of the drowning child, thinking about whether to jump in or not to jump in causes a delay in action and puts the child at more risk.

This also happens with pilots on the flightdeck. Emergency action is performed immediately with little or no thought. For example, pilots memorize bold face items that can be safely performed without any analysis, but which must be done to avoid a higher risk to life or property. However, if the pilot were to think about the situation, even for a few seconds, the bold face items might be delayed just long enough to cause a more severe risk. Non-normal, but not emergency situations often require a great deal of analyzing before arriving at the best solution.

The bioelectrical schematic of how the brain retrieves, organizes, judges, and forms a decision has not been empirically validated, but it has been theoretically expressed (Bass \& Radzio, 2003; Jensen, 1995; Orasanu, 1993). A pilot can choose to attend to a stimulus (radio call, warning horn, airspeed indicator) or to inhibit it. The ability to selectively attend to or inhibit stimuli is of great concern to pilots and those that train them (Telfer \& Biggs, 1988). When this ability is fractured or missing, the instructor must look for reasons why.

Persons with Attention-Deficit Hyperactivity Disorder (ADHD) are of special concern in this regard and more should be done to help student pilots who have been diagnosed and treated since childhood (Barkley, 1990). Although outside the purview of this paper to discuss in depth, the reader is invited to review important findings about ADHD and individuals diagnosed with this disorder in work by Barkley and Grodzinsky (1994), regarding the neuroscience of ADHD, and the hampered development of judgment in ADHD individuals, caused in part by a lagging growth of the frontal lobe (Aylward et al., 1996; Castellanos et al. 1996). It is better for the student pilot and the instructor if issues of judgment are discussed early on in training.

In recent years, some NASA Ames human factors researchers have focused on how pilots learn and retain information. They have looked at how memory affects decisions. Steve Casner has challenged the FAA's approach to Airmen General Knowledge testing, because pilots often memorize the answers to questions posted on the Internet and during a test they select answers that match what they have memorized. Casner has pushed for more in depth learning, rather than rote learning. Although his reasoning is on track, it will be difficult for Part 141 flight schools to shift to the in depth method.

There are three general types of memory: short-term, working, and long-term. Information refresh rates for short-term memory are about every 20 seconds, while refresh rates for longterm memory are measured in months or years or maybe the life of the host (Hubbard, 2000). Working memory is what is used for everyday task performance, and it is a marriage of shortterm and long-term memory operations (Baddeley, 1999). In pilot training, it is the instructor's job to introduce the student to the uses of these types of memory, even though not mentioning them, and then to help the student pilot hone his or her skills of recall (Telfer \& Biggs, 1988). As an aside, Telfer is still being referenced today, even though his work appears to be dated. His insights, as well as Biggs' insights, were not tied to one formula or one design, but were more practical and pilot-friendly.

Instructors play a vital role in judgment development, because they can select methods of instruction that build the student's memory (see Part 2 of this paper). Orderly development of long-term memory has a direct impact on how well a student pilot will do when the instructor is not around to field questions. From a constructivist point of view, the environment in which a learner is placed has an enormous influence on what is learned. Learning involves the constructing of meaning (Clark, 2005). Instructors have the ability to create the right environment and to assign meaning to the objects, events, and tasks that reside within that environment. These assignments of meaning can be grouped with other meanings to create a schema, or a collection of meaningfulness centered on a single subject (Anderson, 1996; Baddeley, 1999).

A schema can be a Gestalt-an indivisible pattern-but it is more likely to be an arrangement of objects of knowledge that freely attach 
themselves to each other and yet are not required to stay glued together (Anderson, 1996; Hawkins, 1987). This freedom to associate or disassociate knowledge elements is intuitively possible, but it is not yet empirically validated, by observing actual bits of knowledge move about in the brain. In lieu of actual observation, cognitive scientists have used many types of tests as a means to reveal how knowledge is acquired. Some of those tests have been in judgment training (Jensen, 1995).

The retention of special emergency procedures, say for takeoff, is one example of how pilots combine knowledge for a specific purpose, because it is not possible to discuss options when the emergency condition (engine failure at rotate speed) requires an immediate decision. To ensure a margin of safety even in the worst conditions, pilots memorize a sequence of productions, which Anderson (1996) called compositions or proceduralizations. Although Anderson's work has evolved over time, the general structure of cognition, in his view, is the same. Not only is the knowledge retained in long-term memory, it is ordered in a special way so that if the right cue were present, the pilot would automatically react. In the presence of the cue or the excitation, compositions in long-term memory flood working memory as if data were dumped en masse. Sensemaking is already predetermined, because with the composition comes a complete environmental picture. This is why simulator training is required for most types of pilot learning.

As an individual builds knowledge and experience, he or she also builds judgment: the ability to make a choice that is nearer pole $\mathrm{A}$ or to make a choice that is nearer pole $\sim \mathrm{A}$. Good flight programs build knowledge and experience in an intentional way, similar to how most constructivists approach the learning environment (Clark, 2005). Information gained during pilot training is stored in three ways: for immediate use and then forgotten (telephone numbers, addresses, and radio frequencies), for use during an event and then partially forgotten (instrument approach altitudes and courses, or directions to a destination), and for use any time in the future (airspeed for slow flight, social security number, or mother's maiden name) and mostly unforgotten. As regards forgotten information, think of forgotten information as bits of knowledge disconnected from their meaningfulness as it was in the past. Since they have become disconnected from meaningfulness, they might not be recalled as in their previous sense-making state. For example, it may have mattered that you knew your locker combination when you were in high school, but when you did not need to remember it, the knowledge of the combination of numbers became disconnected from its relevance. For all practical purposes, it has been forgotten, even though in your brain's cognitive space it is very present.

During pilot training, student pilots acquire new knowledge, which can be stored in a very selective way, if the student, with the instructor's help, builds associations between previously acquired knowledge and newly acquired knowledge (Telfer \& Biggs, 1988). For example, driving a car and taxiing an airplane to the runway are similar activities, since both require steering and following a pathway to a destination and both involve operating a vehicle. What has been learned in past experience while operating an automobile can be used or transferred by the brain to build new relationships, or new schema. With much practice, millions of prototypes, collections of memory (schema), can be created and stored for later use. In the presence of a problem, these specially created prototypes will present as the first options for problem solution if there has been sufficient practice beforehand. Figure 1 illustrates one view of how this might happen.

Having defined tensional meaningfulness, having given an operational definition to judgment, and having presented some of the more popular theories on how one arrives at the best decision, it is time to order the space between the opposing poles of $\mathrm{A}$ and $\sim \mathrm{A}$. So far, there is chaos. But, by using logic, Set Theory, and Venn diagrams, one can identify the poles, and all the intervening space.

\section{Defining Cognitive Boundaries: Venn Diagrams}

J. Venn's contribution to logical argumentation is the Venn diagram: a means to visually display logical arguments without the logical or mathematical notation normally associated with statistical representations of probability (Hays, 1994). Visually displaying a logical induction has its merits, as will be demonstrated.

A Venn diagram is a handy way to explain how one phenomenon relates to another 
phenomenon. In some literature, as in Hays (1994) and again in Dekker (2005), phenomena are events. All literature on Venn diagrams will have to address its basic principles, so newer literature is no more meaningful than older descriptions of this method. Hays is a statistician and Dekker is a cognitive psychologist. Both are constrained by Venn's illustrations. Both Hays and Dekker have found Venn's work helpful in debunking illogical thinking.

One concept that needs to be analyzed in depth is situation awareness. Often mistakenly assumed to be a single event, the term is actually an array of events which interact and change the end state of situation awareness. Venn's diagram and the helpful notation of set theory help give order to the chaos between A and $\sim$ A.

Situation Awareness Training. For example, if one wished to illustrate situation awareness (SA) as a Venn diagram, it could be presented as two concentric ellipses within a defined space resembling Figure 4. The larger ellipse is labeled ideal situation awareness and the interior ellipse is labeled actual situation awareness. A version of this same illustration is featured in Dekker's Ten Questions About Human Error (2005). Put in equation form (see Equation 1), and taking into effect that relationships are a factor $(f)$ of interactions between events, situation awareness appears to be simply deduced. Whatever remains after subtracting actual SA from ideal SA, is a loss of SA-considering that the result is a factored quantity.

But Dekker does not agree with this description, for the reasons stated earlier. Situation awareness is not a single event, but at least 22 separate events (Dennehy \& Deighton, 1997). Situation awareness is often associated with whether an airplane pilot is aware of his or her position relative to other entities within a column of airspace (Endsley, 2000). Since losing SA can be dangerous, pilots need to learn how to control all the events within the conceptual field of situation awareness. However, if training to mitigate the effect of SA relies on inaccurate presentations, as Equation 1 shows and Figure 4 illustrates, aircrew will be left without a means to improve SA. Trainers might need to revise their course objectives for situation awareness training, if lesson plans do not describe SA accurately.

Loss of SA = $f$ (large ellipse - small ellipse)

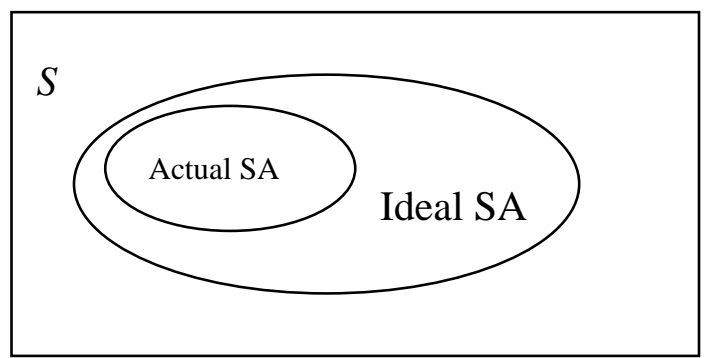

Figure 4. Venn Description of Situation Awareness (adapted from Dekker, 2005, p. 92)

\section{Defining the Problem in Space $S$}

Venn diagrams provide a simplified view of more complex interactions. To understand the more complex interactions, one needs to turn to Set Theory for help. Set Theory resides within the disciplines of Mathematics and Statistics. Statistical representations of Set Theory are more meaningful for this essay and will be used to describe the interactions between events. Probability Theory will be used to express ideas that are and are not present within a notional space. Set Theory has also been used to create categorical syllogisms, or logical arguments with statements of what is true or false. Logic is also represented in the following descriptions of events within a described space. This mathematical/statistical approach to training is different from many other decision-making approaches, because it has the capacity of depicting judgment as being both behaviorally descriptive and philosophically logical.

Whether one analyzes, associates, or just applies rules to solve a problem, all problems and their solutions occupy a finite space (Figure 5), within a larger space where all problems and solutions pertaining to piloting aircraft exist (Figure 6). The arrangement of problems in Figure 6 is not indicative of the way they really exist in our brain, but it does illustrate the notion that problems and their solutions can occupy space together.

Based on Probability Theory all problems and all solutions theoretically and probabilistically exist in the same space $S$ at the same time. For each partition $P$ within space $S$, space $P=\varnothing$ (null set) and space $P=f(p(\mathrm{~A} \sim \mathrm{A})$ or $p(\mathrm{~B} \sim \mathrm{B})$ or...p(N N)). Partition $P$ also equals the factor $(f)$ of the probability of the null set of each pairing ( $p(\mathrm{~A}$ and $\sim \mathrm{A})=\varnothing, p(\mathrm{~B}$ and $\sim \mathrm{B})=\varnothing$, and so on to $\mathrm{p}(\mathrm{N}$ and $\sim \mathrm{N})=\varnothing)$ (Colle \& Reid, 1997). An 
objective truth is not known, only theorized to exist probabilistically.

Philosophically this theoretical approach does not necessarily confirm a realist's view of the material world, where there is an objective truth out there that only needs to be discovered (Dekker, 2005). Believing that there is only an objective truth would defeat the purposes of a Venn diagrammatic view of problems and their solutions, as illustrated in this paper. Although a best fit approach to problem-solving is often sought, problems seldom present in the same way as they did in the past, which forces trainers of pilots to present alternative solutions even to welldefined problems, in case events do not unfold as they did before.

Therefore, during any flight (space $S$ ) there is a probability that a problem $\left(P_{1}\right)$ will occur or not occur $\left(\sim P_{1}\right)$. If a problem $\left(P_{1}\right)$ does occur, it will be solved by using what has already been stored in long-term memory. The orderliness of the solutions depends on how careful the instructor or classroom professor was in helping the students imprint proposed solutions, which can also be construed as part of judgment training. Orderliness is also dependent on an individual's past experience. Since it is difficult to assess exactly how students-in an earlier time-formed their solutions and stored them for later use, it is even more imperative for trainers to guide discussions about solutions to a problem, where each student has an opportunity to orally present his or her solution.

Several probability statements can be made about Figure 5. First, A and B and C are within space $P$, but are not space $P$ (Hays, 1994). They do not exist outside the problem, but they also do not define the problem, only the solution possibilities. For well-defined, ill-defined, and rule-based problems, the problem and its solution are theoretically linked and exist in partition $P$. When a student is presented with a problem, he or she will apply the appropriate solution, if the event has been previously practiced; or if he or she is presented with a novel problem he or she will improvise, by trying alternatives until one solves the problem. Therefore, one can say that (A or $\mathrm{B}$ or $\mathrm{C}) \sim P$; $(p(\mathrm{~A})$ or $p(\mathrm{~B})$ or $p(\mathrm{C})) \sim p(P)$ (Hays, 1994). This notation directly affects test construction and will be discussed later in Part 2 of this paper.

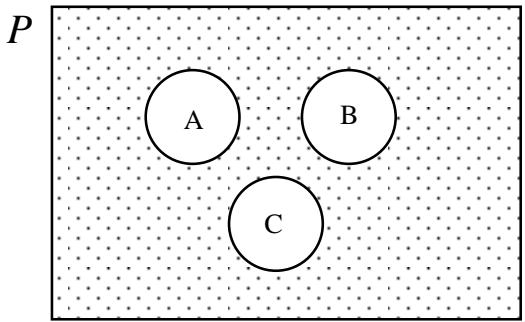

Figure 5. Problems/Solutions within Partition $\mathrm{P}_{\mathrm{n}}$ within Space $S$ as mutually exclusive (Space $S$ not shown)

\begin{tabular}{|l|l|l|l|l|}
\hline$P_{1}$ & $P_{7}$ & $P_{3}$ & $P_{4}$ & $P_{5}$ \\
\hline$P_{6}$ & $P_{7}$ & $P_{8}$ & $P_{9}$ & $P_{10}$ \\
\hline$P_{11}$ & $P_{1}$ & $P_{12}$ & $P_{14}$ & $P_{\mathrm{n}}$ \\
\hline
\end{tabular}

Figure 6. All Possible Problems Related to Piloting Aircraft (Partitioned) (Space $S$ is shown)

Situation awareness, once again, provides a concrete example of how A, B, and C interrelate. Dennehy and Deighton (1997) inter alia listed, stress, workload, spatial awareness, and time perception as distinctive parts of SA. There is an expected interrelationship between these parts, but it is not always so. If $\mathrm{A}=$ stress, and $\mathrm{B}=$ workload, and $C=$ time perception, then for partition $P$ (the problem set), A or B or $\mathrm{C}$ can at one instance be separate events unrelated to SA, and at another instance be interconnected events directly related to SA (A and B and C). Theoretically, these events can simultaneously be related and unrelated to SA. If this simultaneity did not exist, then none of these sub-events could be examined as being separate and a part of SA. In judgment training, being able to discuss each sub-event helps students understand its significance and its relationship to other subevents.

Second, all the solutions in Figure 5 are mutually exclusive, such that $p(\mathrm{~A}) \sim p(\mathrm{~B}$ or $\mathrm{C})$; $p(\mathrm{~B}) \sim p(\mathrm{~A}$ or $\mathrm{C})$; and $p(\mathrm{C}) \sim p(\mathrm{~A}$ or $\mathrm{B})$ (Hays, 1994). The probability of space $P$ is not $A$ or $B$ or $\mathrm{C}(p(P) \sim p(\mathrm{~A}$ or $\mathrm{B}$ or $\mathrm{C})$ ) (Hays, 1994). Problems must be differentiated from solutions, but there should not be an exclusion of either from partition $P$. It is just as important to declare that a possible solution is wrong as to declare that a solution is right, or the best. When a flight instructor takes the time to explain why other solutions are not appropriate, the student is learning how to 
discriminate among several options and is building judgment.

Complex solutions might involve the intersection of two possibilities (A and B, A and $\mathrm{C}$, or $\mathrm{B}$ and $\mathrm{C}$ ). This is particularly true for a proper analysis of situation awareness. In Figure 7 there is a combining of solution A and solution B in partition $P$, such that the intersection of $A$ and B (AB) represents a solution that is not $A(\sim A)$ and not $\mathrm{B}(\sim \mathrm{B})$, but a part of both. The remaining area not in the intersection can be presented as $A$ and $\sim \mathrm{B}$ or $\mathrm{B}$ and $\sim \mathrm{A}$ (Hays, 1994). The skill of combining solutions to form a new solution must be first understood in the classroom and then practiced until thoroughly learned.

Situation awareness is a complex concept, and its very makeup is built upon interrelationships between events, such as stress, workload management, and time perception. Each event contributes a part of itself to a part of another event. Stress and time perception have a cause-effect relationship, where a perception of time causes stress and where stress causes a perception of time.

In Figure 7, relationships between events (A and $\mathrm{B}$ ) appear to be formed by what $\mathrm{A}$ and $\mathrm{B}$ have in common and what $\mathrm{A}$ and $\mathrm{B}$ do not have in common. If a line were drawn between the center of event $\mathrm{A}$ and the center of event $\mathrm{B}$, all possible relationships between $\mathrm{A}$ and $\mathrm{B}$ could be described using the theory of tensional meaningfulness. Where the line crosses the interrelated part shown as $A B$, one can expect to find the highest degree of fusion of $\mathrm{A}$ and $\mathrm{B}$.

This tensional meaningfulness must be intentionally created during pilot training. Clark (2005) quoted from a study by Hamm, making the connection between experience and the intentionality of knowledge-building during that experience. The end points must be absolutely clear, and all the intervening events must be put in proper perspective to those end points. For example, during an icing scenario (no deicing boot or bleed air on the wings), where the pilot finds him or herself in icing conditions, he or she must make a decision. Staying in the icing conditions is not a good decision. Therefore, the decision to exit icing can be represented as a probability $p(\mathrm{~A})$ and the decision to stay in the icing and do nothing can be represented as a probability $p(\sim \mathrm{A})$.

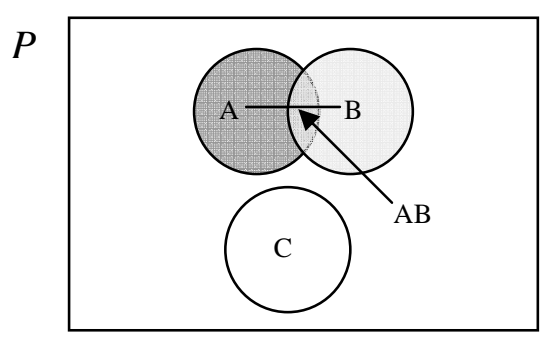

Figure 7. Combining Solutions

What the instructor needs to do is present the points in opposition (A and $\sim \mathrm{A}$ ) and then ask the student why one decision is better than the other. How the student explains his or her answer is the moment the instructor identifies judgment. Judgment in this example is neither A or $\sim \mathrm{A}$, but is an intervening element between the two.

Figure 8 illustrates how a trained pilot would approach a problem: in this case it is an icing problem. Before a problem exists, it is theoretically out there, out of sight and mind. As soon as it becomes apparent to the pilot that a problem exists, he or she will begin to form a solution, from an array of many solutions, all the while keeping in mind the nature of the problem. The problem $\left(P_{1}\right)$ remains indistinct among all the events discernable during flight, until the point in space-time when the problem becomes conspicuous (salient), when the status quo of normal flight operations is interrupted and attention is drawn to the interruption.

Notice that after the intrusion, by identifying partition $P$, one can begin to test alternative solutions systematically for problem $P_{1}$. For each $\mathrm{A}$ and $\sim \mathrm{A}$ decision, there is an intervening judgment that indicates why A or $\sim \mathrm{A}$ was chosen. The same is true for all alternatives, such that $\mathrm{B}$ or $\sim \mathrm{B}, \mathrm{C}$ or $\sim \mathrm{C}$, and so on are all considered. By examining the judgment operating between each decision, the instructor can surgically remove erroneous thinking or implant proper thinking. In terms of the more complex architecture behind the act of deciding refer to Anderson (1996). Some of his examples, particularly elements of his Adaptive Control of Thought (ACT) process, follow similar logical patterns as those described herein.

One proposed way that the brain systematically accepts (attends to) or rejects (inhibits) possible solutions is illustrated in centersurround fashion, thoroughly explained in Dagenbach and Carr (1994). There are other 
proposed ways, such as parallel distribution theory, but for this paper center-surround will take precedence. As regards center-surround, the intrusion $\left(P_{1}\right)$ takes center stage and all the alternatives are immediately placed around it, waiting for the individual to decide which solution remains and which solutions are rejected (Dagenbach \& Carr, 1994). In Figure 8, the "after" part of the illustration shows the problem ( $P_{1}$ from Figure 6$)$ in the middle, surrounded by possible solutions. The efficacy (power to cause an effect) of a solution is tested in probability terms, such that for space $P$ and problem $P_{1}$, the tension of $\mathrm{p}(\mathrm{A})$ or $\mathrm{p}(\sim \mathrm{A})$; $\mathrm{p}(\mathrm{B})$ or $\mathrm{p}(\sim \mathrm{B})$; $\mathrm{p}(\mathrm{C})$ or $\mathrm{p}(\sim \mathrm{C})$; $\mathrm{p}(\mathrm{D})$ or $\mathrm{p}(\sim \mathrm{D})$; and $\mathrm{p}(\mathrm{E})$ or $\mathrm{p}(\sim \mathrm{E})$ are all tested.

If the instructor pilot has properly trained his or her student pilots, they all should be considering the same number of alternatives and accepting or rejecting the same solutions. This can be verified in several ways. First, during a ground evaluation or a debriefing session, the instructor can ask the student to recall the steps that he or she would take if confronted with a problem, say icing. This oral interview is useful in that the student has all the time needed to fully explain what he or she would have done. The debriefing or ground evaluation method can also be conducted after a simulator session or flight in the airplane. Second, students can be assessed while performing in a simulator training session. The problem will appear at some point during the session and in real time the student will follow through with his or her solution to the problem. This type of assessment is better than the post hoc debriefing, since the level of extrinsic interference (freezing the problem) can be controlled.

The theoretical part of this paper has illustrated several key aspects of judgment training. Decisions, when placed in opposition, can reveal intervening judgment strategies that are neither polarized to one decision or its polar opposite decision. The illustration of the magnet and iron filings presented a good picture of how disorder (layer of iron filings) could be brought into order (magnetic field) in the presence of another set of objects (bipolar magnet). When a pilot is presented with a problem, apparent disorder in the brain suddenly becomes organized in the presence of oppositional factors such as A and $\sim \mathrm{A}$. In the presence of an icing problem, the decision to exit the icing condition (A) is weighed against its oppositional equivalent of staying in the icing condition $(\sim \mathrm{A})$.

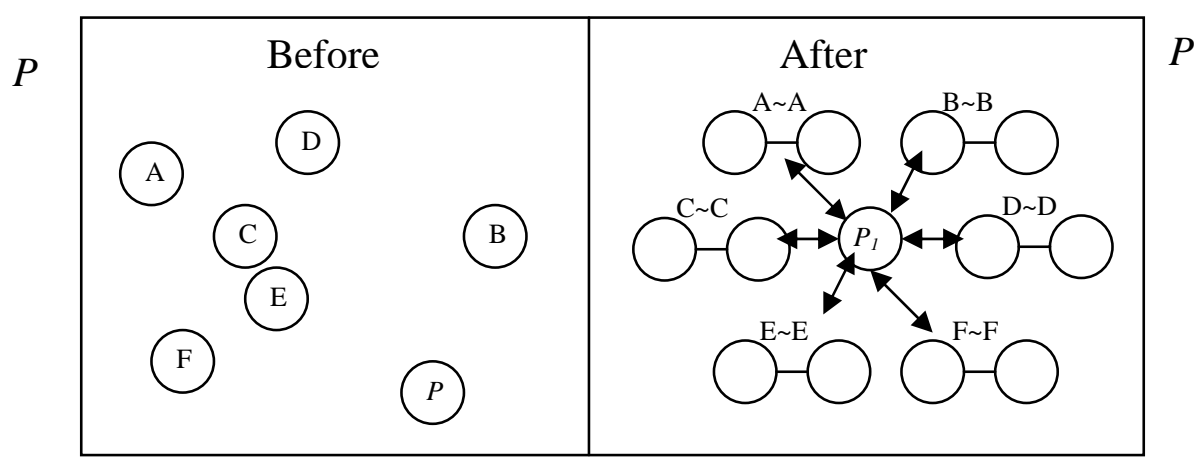

Figure 8. Problem Recognition at the Point of Salience

We also know that a properly trained student pilot will have the judgment to make decisions that are knowledge-based (ill-defined problem), knowledge-based (well-defined problem), or rulebased. If the instructor or professor has been careful about how he or she approached each decision type, judgment will have been developed in these three unique ways.

The second part of this paper translates theory into practice, giving the practitioner plenty of ideas on how to develop and assess the training.
Each decisional type (Mauro et al., 2001; Orasanu, 1993) will be described in terms that instructional designers, flight instructors, and academic faculty will find handy when writing courseware.

\section{PART 2: USING SET THEORY TO DETERMINE INSTRUCTIONAL CONTENT}

Throughout the first part of the paper theory and practice were commingled intentionally. Theoretical equations are helpful, but plain 
English descriptions are more helpful to the practitioner. Illustrations can be helpful, if they express an intuitive notion. The magnetic field illustration presented in Figure 2 needs little explanation. Venn diagrams look simple visually, but they can represent a complicated set of operations or probabilities. If you are an instructor, you are waiting to see a clear depiction of how theory can be translated into practice in the classroom or simulator training room or airplane.

What follows is a practical guide for course developers, flight instructors, and collegiate aviation professors. Orasanu's (1993) three categories of decisions will be used to differentiate between and among the approaches to problem-solving, judgment development, and decision-making. The theoretical equations for each decision type will be presented first, followed by the practical guide. Within the practical guide, the reader will find instructions for the classroom and simulator (if appropriate), suggestions for companion texts, types of testing, and testing strategies.

This practical guide is somewhat different from other instructional guides, in that it presents the logical progression of instruction in terms of probability statements and Set Theory. Other instructional methods, such as Dick, Carey, and Carey (2001) or that used by the International Civil Aviation Organization [ICAO] (1991) ${ }^{1}$ use a systematic approach based on behavioral objectives, not cognitive objectives, such as are needed in judgment training.

Theoretical relationships can also be used to create test questions, and determine whether the correct and incorrect answers are logically presented: whether they are mutually exclusive.

\section{Knowledge-Based (Ill-Defined Problem)}

Theoretical Equations and Practical Guide. If space $S=p\left(\mathrm{P}_{1}\right.$ and $\mathrm{P}_{2}$ and $\left.\ldots \mathrm{P}_{\mathrm{n}}\right)$; and space $S=$ $p\left(\sim \mathrm{P}_{1}\right.$ or $\sim \mathrm{P}_{2}$ or $\left.\ldots \sim \mathrm{P}_{\mathrm{n}}\right)$; and space $P_{1}=p(\mathrm{~A} \sim \mathrm{A}$ and $\mathrm{B} \sim \mathrm{B}$ and $\ldots \mathrm{N} \sim \mathrm{N})$; or space $P_{1}=p(\mathrm{~A} \sim \mathrm{A}$ or $\mathrm{B} \sim \mathrm{B}$ or ...N N) then:

- Instruction Classroom: Present as many problems as possible during the classroom portion of the course $\left(\mathrm{P}_{1} \ldots \mathrm{P}_{\mathrm{n}}\right)$. Follow up with conditional statements (this problem will

\footnotetext{
${ }^{1}$ As of 2005, the $2^{\text {nd }}$ edition of the Training

Development Guideline was still current.
}

happen when...) $\left(P_{1}=p(\mathrm{~A} \sim \mathrm{A}\right.$ and $\mathrm{B} \sim \mathrm{B}$ and $\ldots \mathrm{N} \sim \mathrm{N})$. For each problem, have the class list as many solutions as possible. Next, present a scenario for one problem and have the students list alternative solutions $(A \sim B \sim C \sim D \sim E \ldots)$. Finally, have the students deselect alternative solutions that are not the best fit, but have the students explain why these alternatives are not the best fit.

- Instruction Simulator: Use these same problems as the underlying theme for simulator sessions during the lab portion of the same course.

- Companion Text: AC 60-22, ADM; Jensen (1995)

- Testing: Knowledge tests in classroom and practical tests in simulator (required)

- Testing Strategies for Simulator: Each student should complete several sessions, where various scenarios are used to probe the student's problem-solving ability. To determine judgment, use the debriefing to interview the student. Ask the student to explain why he or she chose a particular solution to the problem. Where the student's judgment is effective, reinforce this behavior. Where the student's judgment is ineffective, explain why his or her judgment was ineffective. If ineffective judgment is found, during the debriefing provide the student with an additional scenario (similar to the one experienced) and have them explain how he or she would solve the problem. Reinforce effective judgment.

\section{Knowledge-Based (Well-Defined Problem)}

Theoretical Equations and Practical Guide. If space $S=p\left(\mathrm{P}_{1}\right)$; space $S=p\left(\sim \mathrm{P}_{2}\right.$ or $\sim \mathrm{P}_{3}$ or $\left.\ldots \sim \mathrm{P}_{\mathrm{n}}\right)$; or space $P_{1}=p(\mathrm{~A} \sim \mathrm{A})$; or space $P_{1}=$ $p \sim(\mathrm{B}, \mathrm{C}, \mathrm{D}$, or...N) then:

- Instruction Classroom: Since the focus is on only one problem that has been observed and resolved in the past, instruction can be narrowly focused. Provide basic knowledge of the problem, perhaps from NTSB accident reports. Differentiate this specific problem from other problems that might overlap. Finally, describe the recommended best fit. During guided discussion, present a variety of scenarios where this problem is featured. Have the students apply the best fit solution to each scenario. Include the entire class. 
- Instruction Simulator: During simulator training, provide scenarios with only one major problem and only one best fit solution. During the debriefing interviews, discuss other scenarios that are similar and have the student provide a solution. Change the conditions of each scenario, so that the students have practice applying best fit solutions in different settings.

- Companion Text: AC 60-22, ADM; Jensen (1995)

- Testing: Knowledge tests in classroom, practical tests in classroom, practical tests in simulator.

- Testing Strategies for Classroom: Simple, well-defined problems provide an opportunity for testing in the classroom, because best fit solutions need to be reinforced. At the beginning of each classroom session, present the problem of the day. Have the students write down their solution. After the students finish their written solution, select several students to read their solution to the class. Where there are errors in judgment, the instructor can provide rationale for the judgment that best fits the scenario. Comprehensive testing in this way is too timeconsuming and ineffective, since not all scenarios can be properly debriefed.

- Testing Strategies for Simulator: see Instruction Simulator.

\section{Rule-Based (Condition-Action Rules)}

Theoretical Equations and Practical Guide. If Space $S=p\left(\mathrm{P}_{1}\right)$; or Space $P_{1}=p(\mathrm{~A}) \sim \mathrm{B}$ or $\sim \mathrm{C}$ or $\ldots \sim \mathrm{N}$ then:

- Instruction Classroom: Rules, if not connected to a problem or scenario, are difficult to learn. Therefore, a problem (Condition) needs to be present, where the solution is the application of a rule (Action Rule). Studying rules without problems is not only boring, it is also ineffective. Where student pilots run into trouble in their judgment is when they do not see that a rule needs to be applied. For example, when a pilot is preparing for a solo cross-country flight, the rules say that the weather has to be checked, but there is nothing in real life that stimulates the knowledge of this rule. Therefore, provide the students with personal go/no-go checklists that incorporate rules with decisions needing to be made for any VFR or IFR flight. Many such checklists exist.

Rules are often associated with their Part number from the Federal Aviation Regulations (FARs). The rule is more important than the Part number; however, where evaluators and instructors put an emphasis on memorizing Part numbers, you will have to spend extra time reinforcing this association.

- Companion Text: Title 14 CFR (FARs); Aviation Law text (Hamilton and Gesell discuss FARs in their texts); Jensen (1995).

- Testing: Knowledge-based, paper and pencil; matching; multiple-choice; Simulator sessions are not required.

- Testing Strategies for Classroom: If rules must be associated with actual references from the FARs, administer quizzes at the beginning and ending of every session where these rules are presented. Every week, start the class with a problem needing a rule applied. Have the students write down that rule and its reference. Collect the papers and grade them. Correct the papers and pass them back to the students. If a student failed to give the right rule and reference, make that student provide the correct rule and reference on a retake of the test. I suggest that these papers not be counted as part of the grade. At the end of the block of lessons on the FARs, give a test with a representative sample of those rules that most apply to flying by student pilots. When grading, do not offer the correct rule and reference if the student made an error. Make the student who erred provide the correct rule and reference. For rule-based learning, the student must always be corrected if an error occurs. Therefore, since following rules is imperative to safe flight, I suggest raising the minimum passing grade to 85 . Any score below 85 will require the student to correct the test to $100 \%$. Of course this scoring regime will need to appear in the syllabus and it will need some explaining. If there are questions, contact the author of this essay.

\section{CONCLUSION}

When complex terms are relegated to qualitative narrative, sense-making depends on the skill of the writer and the ability of the reader to 
understand what the author had intended. Cognitive psychologists have tried to depict the sequence of events, and the overlapping elements of decision-making for airplane pilots for better than three decades. Jensen (1995) and Orasanu (1993) were some of the earlier researchers who concentrated on how pilots make decisions. Much of what they have presented in academic journals has been built upon by others, but the more recent contributions have not substantially replaced earlier notions of judgment and decision-making.

This essay on the theoretical mechanisms of judgment training introduced tensional meaningfulness as a way to identify and separate judgment from decisions. It stated that if two poles of any problem could be identified (A and $\sim A$ ), then all intervening expressions of solution, relative to the problem, could be examined and shown to be either closer to the best solution or farthest away from the best solution. The Set Theory expression of this relationship, when depicted as a Venn diagram, had shown two circles within a set space, with an overlapping area along the axis between the centers of each circle (Figure 7). The area combining circle $\mathrm{A}$ and circle $\mathrm{B}$, or $\mathrm{AB}$, described how the two events related; but the shared area also indicated the possibility that more than one solution could be found and implemented relative to any problem.

These findings were the basis for the development of a more practical guide for judgment training, found in Part 2.

Set Theory and Probability Theory could be used to more accurately describe complex concepts, such as situation awareness or complacency; and the logical progression of Set Theory would provide a means to systematically analyze course materials of all types. 


\section{REFERENCES}

Anderson, J. R. (1996). The architecture of cognition. Mahwah, NJ: Lawrence Erlbaum Associates.

Aylward, E. H., Reiss, A. L., Reader, M. J., Singer, H. S., Brown, J. E., \& Denckla, M. B. (1996). Basal ganglia volumes in children with attention-deficit hyperactivity disorder. Journal of Child Neurology, 11, 112-115.

Baddeley, A. (1999). Essentials of human memory. East Sussex, England: Psychology Press Ltd, Publishers.

Barkley, R. A. (1990). Attention-deficit hyperactivity disorder: A handbook of diagnosis and treatment. New York: Guildford Publications.

Barkley, R. A., Grodzinsky, G. M. (1994). Are tests of frontal lobe functions useful in the diagnosis of attention deficit disorders? Clinical Neuropsychologist, 8, 121-139.

Bass, E. J., \& Radzio, M. (2003). Applying Stewart's 1990 decomposition of human forecasting performance to a simulated air traffic conflict prediction task. In R. Jensen (Ed.) Proceedings of the $12^{\text {th }}$ International Symposium on Aviation Psychology (pp. 76-81). Dayton, Ohio.

Beaubien, J. M., \& Baker, D. P. (2002). Perceptions of and experience in Crew Resource Management (CRM) training. Proceedings of the 2002 Society of Automotive Engineers' World Aviation Congress and Display. Washington, D.C.: Society of Automotive Engineers.

Beneigh, T, \& Hubbard T. P. (2007). CRM Vectors 2007. International Journal of Professional Aviation Training \& Testing Research, 1, 29-37.

Berlin, J. I., Gruber, E. V., Holmes, C. W., Jensen, P. K., Lau, J. R., Mills, J. W., et al. (1982). Pilot judgment training and evaluation. Daytona Beach, FL: Embry-Riddle Aeronautical University. (NTIS No. AD-A117508)

Castellanos, F. X., Geidd, J. N., Marsh, W. L., Hamburger, S. D., Vaituzis, A. C., Dickstein, D. P. et al. (1996). Quantitative brain magnetic resonance imaging in attention-deficit hyperactivity disorder. Archives of General Psychiatry, 53, 607-616.

Clark, J. (2005). Explaining learning: From analysis to paralysis to hippocampus. Educational Philosophy, 37(5), 667-687.

Colle, H. A., \& Reid, G. B. (1997). Mental workload measurement structures. In D. Harris (Ed.) Engineering psychology and cognitive ergonomics: Vol. 1 transportation systems, (pp. 253-260). Aldershot, Hants, England: Ashgate Publishing Ltd.

Cook, W., Beneigh, T., \& Clark, R. (2001). CRM-Identifying and presenting what is most critical. In R.

Jensen (Ed.) Proceedings of the $11^{\text {th }}$ International Symposium on Aviation Psychology (pp. 1-6). Columbus, Ohio.

Dagenbach, D., \& Carr, T. H. (1994). Inhibitory processes in perceptual recognition: Evidence for a center-surround Attentional mechanism. In D. Dagenbach \& T. H. Carr (Eds.) Inhibitory processes in attention, memory, and language (pp. 327-355). San Diego, CA: Academic Press, Inc.

Dekker, S. W. A. (2005). Ten questions about human error. Aldershot, England: Ashgate Publishing Ltd.

Dennehy, K., \& Deighton, C. D. B. (1997). The development of an interactionist framework for operationalising situation awareness. In D. Harris (Ed.) Engineering psychology and cognitive ergonomics: Vol. 1 transportation systems, (pp. 283-290). Aldershot, Hants, England: Ashgate Publishing Ltd. 
Department of Transportation. (1991). Aeronautical decision making (Advisory Circular No. 60-22). Washington, D.C.: Federal Aviation Administration.

Department of Transportation. (2004). Crew resource management training (Advisory Circular 120-51E). Washington, D.C.: Federal Aviation Administration.

Dick, W., Care, L., \& Carey, J. O. (2001). The systematic design of instruction $\left(5^{\text {th }}\right.$ ed.). New York: Addison-Wesley Educational Publishers Inc.

Diehl, A. E., \& Lester, L. F. (1987). Private pilot judgment training in flight school settings. DOT/FAA/AM-87/6. Washington, D.C.: FAA.

Dismukes, R. K., Berman, B. A., \& Loukopoulos, L. D. (2007). Limits of expertise: Rethinking pilot error and the causes of aircraft accidents. Aldershot, UK: Ashgate Publishing.

Endsley, M. R. (2000). Theoretical underpinnings of situation awareness: A critical review. In M. R. Endsley \& D. J. Garland (Eds.) Situation awareness analysis and measurement (pp. 3-32). Mahwah, NJ: Lawrence Erlbaum and Associates.

Gardner, H. (1999). Intelligence reframed: Multiple intelligences for the $21^{\text {st }}$ century. New York: Basic Books.

Goleman, D. (1995). Emotional intelligence. New York: Bantam Books.

Hawkins, F. H. (1987). Human factors in flight ( $2^{\text {nd }}$ ed.). Aldershot, England: Ashgate Publishing Ltd.

Hays, W. L. (1994). Statistics. Fort Worth, TX: Harcourt College Publishers.

Hoover, A. L., \& Russ-Eft, D. F. (2005). Effect of concurrent task management training on single pilot task prioritization performance. International Journal of Applied Aviation Studies, 5(2), 233-251.

Hubbard, T. P. (2000). Effect of an inhibition testing model on private pilot, airplane single-engine land, ground school students. (Doctoral dissertation, Oklahoma State University, 2000). Dissertation Abstracts International-B 61/09, p. 5018.

International Civil Aviation Organization. (1991). Training development guideline ( ${ }^{\text {nd }}$ ed.). Montreal, Canada: author.

Jacobson, C. N., Mosier, K. L., \& Sethi, N. (2003). Coherence and correspondence decision making theories in aviation: A study of pilot incident reports. In R. Jensen (Ed.) Proceedings of the $12^{\text {th }}$ International Symposium on Aviation Psychology (pp. 598-602). Dayton, Ohio.

Jensen, R. S. (1995). Pilot judgment and crew resource management. Aldershot, England: Ashgate Publishing Ltd.

Lauber, J. K. (1993). Preface. In E. L. Wiener, B. G. Kanki, \& R. L. Helmreich (Eds.), Cockpit resource management, pp. xv-xviii. San Diego, CA: Academic Press.

Lofaro, R. J., \& Smith, K. M. (2001). Operational decision-making: Integrating new concepts into the paradigm. In R. Jensen (Ed.) Proceedings of the $11^{\text {th }}$ International Symposium on Aviation Psychology (pp. 1-6). Columbus, Ohio.

Loukopoulos, L. D., Dismukes, R. K., \& Barshi, I. (2001). Cockpit interruptions and distractions: A line observation study. In R. Jensen (Ed.) Proceedings of the $11^{\text {th }}$ International Symposium on Aviation Psychology (pp. 1-6). Columbus, Ohio.

Mauro, R., Barshi, I., Pederson, S., \& Bruininks, P. (2001). Affect, experience, and aeronautical decisionmaking. In R. Jensen (Ed.) Proceedings from the $11^{\text {th }}$ International Symposium on Aviation Psychology (pp. 1-6). Columbus, Ohio. 
Mulqueen, C., Baker, D. P., \& Dismukes, R. K. (2002). Pilot instructor rater training: The utility of the multifacet item response theory model. The International Journal of Aviation Psychology, 12(3), 287-303.

O’Hare, D. (2003). Aeronautical decision making: Metaphors, models, and methods. In P. S. Tsang \& M. A. Vidulich (Eds.), Principles and practice of aviation psychology pp. 201-237. Mahwah, NJ: Lawrence Erlbaum Associates.

Orasanu, J. M. (1993). Decision-making in the cockpit. In E. L. Wiener, B. G. Kanki, \& R. L. Helmreich (Eds.), Cockpit resource management, pp. 137-172. San Diego, CA: Academic Press.

Reason, J. T. (1990). Human error. Cambridge, England: Cambridge University Press.

Telfer, R., \& Biggs, J. (1988). The psychology of flight training. Ames, IA: Iowa State University.

Tsang, P. S., \& Vidulich, M. A. (2003). Introduction to aviation psychology. In P. S. Tsang \& M. A. Vidulich (Eds.), Principles and practice of aviation psychology pp. 1-19. Mahwah, NJ: Lawrence Erlbaum Associates. 